\title{
David Oliver: What's behind the rise in dementia admissions?
}

\section{David Oliver consultant in geriatrics and acute general medicine}

Berkshire

I recently woke to news headlines claiming that NHS hospitals were admitting " 1000 dementia patients a day" —a rapid increase since 2013 .

The data came from NHS Digital. But the expert commentary, quoted in the Daily Mail and broadcast widely, came from the Alzheimer's Society. ${ }^{2}$ It blamed social care cuts and claimed that dementia admissions generally harmed patients or left them unable to return home.

I care deeply about improving acute and community care in dementia, so I was pleased to see the topic get airtime. I don't want to dampen the impact by nitpicking. But I do have some caveats.

Firstly, it isn't news that many people in hospital beds have dementia or delirium. A decade ago, the NHS Confederation and the Alzheimer's Society reported that in around one in four beds was someone with dementia. ${ }^{3}$ Back in 2009 Sampson and colleagues showed that $42 \%$ of people over 70 admitted to hospital had dementia, and around half had no prior diagnosis. ${ }^{4}$ The Royal College of Psychiatrists has published four rounds of its national audit of care for dementia in general hospitals. ${ }^{5}$ Gaps remain, but we've seen steady improvements and wider adoption of good care systems and processes.

Secondly, since 2012 the NHS in England has had a national payment incentive to ensure that hospitals identify people with dementia and code the cases. ${ }^{6}$ This may partly account for a rise in admissions far higher than the increase in community cases might lead us to expect.

\section{Binary narrative}

Thirdly, the news coverage barely mentioned that the initial emergency attendance or admission is often appropriate, whether or not the patient has dementia. If you have, say, a stroke, hip fracture, severe infection, or metabolic disturbance, acute hospital may often be the safest and best option. There's good evidence for the benefit of ward based, comprehensive geriatric assessment and post-acute rehabilitation for frail older people, including those with hip fracture or stroke. ${ }^{7-9} \mathrm{~A}$ binary narrative of "hospital harmful, community safe" is simplistic and unhelpful.

Fourthly, gaps in health services away from acute hospitals are as important in this story as gaps in social care. Even for conditions labelled as primary or ambulatory care or for "potentially preventable" hospital admissions, we can't assume that current primary and community healthcare models are sufficiently responsive or available. ${ }^{1011}$ This includes end-of-life care, specialist mental health services, and support for care home residents..$^{12-14}$

The "ageing well" component in the NHS long term plan requires faster crisis responses for older people at home, more rapid access to home based rehabilitation, more healthcare provision for care home residents, and more support for carers-all reliant on skilled, multi-professional teams. ${ }^{15}$ However, current capacity is nowhere near sufficient, as the NHS Benchmarking Network's intermediate care audits have shown. The NHS pledge of $£ 4.5 \mathrm{bn}(€ 5.08 \mathrm{bn}$; $\$ 5.56 \mathrm{bn})$ for community health services may be spread thinly with many competing demands, and we have an existing crisis in the community health and care workforce. ${ }^{16}$

My final point? The crisis in social care is undoubtedly worsening, for an ageing population with more people who have dementia and are reliant on care-most of it from family. Social care requires urgent solutions, but not all adults needing social care have dementia. And not all patients with dementia receive or are eligible for social care.

Although their intent is admirable and the publicity important, I do worry that current campaigning by the Daily Mail and the Alzheimer's Society tends to make "social care" and "dementia" completely synonymous, with a narrative and editorial lines to suit. But they are overlapping entities. The health service is part of the problem - and part of the solution.

Competing interests: See www.bmj.com/about-bmj/freelance-contributors. Provenance and peer review: Commissioned; not externally peer reviewed. 
1 Borland S, Spencer B, Dilworth M. Hospitals treat 1000 dementia patients a day because basic social care is so poor they are forced to turn to casualty wards for help. Daily Mail 2019 Aug 20. https://www.dailymail.co.uk/health/article-7373163/Hospitals-treat-1-000dementia-patients-day-basic-social-care-poor.html.

2 Hammond D. Dementia A\&E rise: almost 1000 dementia patients are admitted to A\&E every day, NHS figures reveal. Sun 2019 Aug 20. https://www.thesun.co.uk/news/9757445/ 1000-dementia-patients-nhs-accident-and-emergency/.

3 Oliver D. David Oliver: Progress on dementia in hospital. BMJ 2016;353:i2204. 10.1136/bmj.i2204 27106668

4 Sampson EL, Blanchard MR, Jones L, Tookman A, King M. Dementia in the acute hospital: prospective cohort study of prevalence and mortality. Br J Psychiatry 2009;195:61-6. https://www.cambridge.org/core/journals/the-british-journal-of-psychiatry/article/dementiain-the-acute-hospital-prospective-cohort-study-of-prevalence-and-mortality/ F13ABFD59453D751E1ECC13B1C610067. 10.1192/bjp.bp.108.055335 19567898

5 Royal College of Psychiatrists. National audit of dementia care in general hospitals 2018-2019: round four audit report. 2019. https://www.rcpsych.ac.uk/docs/default-source/ improving-care/ccqi/national-clinical-audits/national-audit-of-dementia/r4-resources/ national-audit-of-dementia-round-4-report-online.pdf?sfvrsn $=775 c 5 b 75 \_6$.

6 Harrison JR. Improving inpatient care for older adults: Implementing Dementia Commissioning for Quality and Innovation (CQUIN). BMJ Open Qual 2017;6:u212202.w4875. 10.1136/bmjquality.u212202.w4875. https://bmjopenquality.bmj. com/content/6/1/u212202.w4875.

7 Ellis G, Gardner M, Tsiachristas A, etal . Comprehensive geriatric assessment for older adults admitted to hospital. Cochrane Database Syst Rev 2017;9:CD006211. https://www. cochrane.org/CD006211/EPOC_comprehensive-geriatric-assessment-older-adultsadmitted-hospital. 10.1002/14651858.CD006211.pub3 28898390

8 Middleton M, Wan B, da Assunçao R. Improving hip fracture outcomes with integrated orthogeriatric care: a comparison between two accepted orthogeriatric models. Age Ageing 2017;46:465-70. 10.1093/ageing/afw232. https://academic.oup.com/ageing/article/46/3/ 465/2681824. 27974304
9 Stroke Unit Trialists Collaboration. How do stroke units improve patient outcomes? A collaborative systematic review of the randomized trials. Stroke 1997;28:2139-44. 10.1161/01.STR.28.11.2139. https://ahajournals.org/doi/10.1161/01.STR.28.11. 2139. 9368554

10 Cowling TE, Soljak MA, Bell D, Majeed A. Emergency hospital admissions via acciden and emergency departments in England: time trend, conceptual framework and policy implications. J R Soc Med 2014;107:432-8. https://journals.sagepub.com/doi/full/10.1177/ $0141076814542669.10 .1177 / 014107681454266925377736$

11 National Audit Office. Reducing emergency admissions. 2 Mar 2018. https://www.nao. org.uk/report/reducing-emergency-admissions/.

12 Wolters A, Santos F, Lloyd T, Lilburne C, Steventon A. Emergency admissions to hospital from care homes: how often and what for? Improvement Analytics Unit. Jul 2019. https:/ /www.health.org.uk/sites/default/files/upload/publications/2019/Emergency-admissionsfrom-care-homes-IAU-Q02.pdf.

13 NHS England. Implementation guide and resource pack for dementia care. 17 Jul 2017. https://www.rcpsych.ac.uk/docs/default-source/improving-care/nccmh/nccmh_dementiacare-short-guide.pdf?sfvrsn=f12f13d8_2.

14 Harris D. Forget me not: palliative care for people with dementia. Postgrad Med J 2007;83:362-6. 10.1136/pgmj.2006.052936. https://www.ncbi.nlm.nih.gov/pmc/articles/ PMC2600060/. 17551065

15 NHS England. Ageing well. https://www.longtermplan.nhs.uk/areas-of-work/ageing-well/

16 Beech J, Bottery S, Charlesworth A. Closing the gap: key areas for action on the health and care workforce. Nuffield Trust. 21 Mar 2019. https://www.nuffieldtrust.org.uk/research/ closing-the-gap-key-areas-for-action-on-the-health-and-care-workforce.

Published by the BMJ Publishing Group Limited. For permission to use (where not already granted under a licence) please go to http://group.bmj.com/group/rights-licensing/ permissions 